Ericka Viviane Pontes Procópio ${ }^{1}$

Camila Guerra Feliciano ${ }^{1}$

Kalina Vanderlei Paiva da Silva ${ }^{1}$

Cintia Regina Tornisiello Katz ${ }^{1}$

${ }^{1}$ Programa do Mestrado em Hebiatria, Faculdade de Odontologia de

Pernambuco, Universidade de Pernambuco. Av. Genera Newton Cavalcante 1650

Tabatinga. 54.753-220

Camaragibe PE Brasil.

erickaviviane@hotmail.com

\title{
Representação social da violência sexual e sua relação com a adesão ao protocolo de quimioprofilaxia do HIV em mulheres jovens e adolescentes
}

Social representation of sexual violence and its relationship with the adherence to the chemoprophylaxis protocol of HIV in young women and adolescents

\begin{abstract}
The scope of this study was to understand the social representations of sexual violence and its relationship with adherence to the chemoprophylaxis protocol of HIV in young women and adolescents. Qualitative research was conducted based on the theory of social representations through recorded interviews with 13 female subjects aged between 12 and 23. It was observed that the social representations about sexual violence exerted a considerable influence on adherence to chemoprophylaxis treatment in the group. The individuals surveyed elaborated images in which the concern caused to the family, discomfort caused by the effects of drugs, change of routine, fear of getting sick, being stigmatized, anxiety and anger, appeared as constant elements, which can lead to the abandonment of treatment. Considering the influence of these representations on treatment, there is a need for greater attention of the health services in relation to these possibilities, and for resources to ensure care based on these different needs. In addition to investing in research into new drugs, it is necessary to invest in qualitative research, providing input for more appropriate care for patients.

Key words Adolescent, Sexual violence, Chemoprevention, Adherence to treatment, Medication, Social representation
\end{abstract}

Resumo O objetivo deste estudo foi conhecer as representações sociais da violência sexual e sua relação com a adesão do protocolo da quimioprofilaxia do HIV em mulheres jovens e adolescentes. Realizou-se uma pesquisa qualitativa, orientada pela teoria das representações sociais, através de entrevista gravada com 13 mulheres, com idades entre 12 e 23 anos. No grupo, observou-se que as representações sociais construídas acerca da violência sexual exerceram uma considerável influência na adesão ao tratamento quimioprofilático. As pesquisadas elaboraram imagens nas quais as preocupações geradas à família, desconfortos causados pelos efeitos dos fármacos, a mudança de rotina, o medo de adoecer, de ser estigmatizada, ansiedade e raiva, apareceram como elementos constantes, podendo acarretar o abandono do tratamento. Considerando a influência dessas representações no tratamento, verifica-se a necessidade de uma maior atenção dos serviços de saúde com relação a estas possibilidades, dispondo de recursos para planejar sua assistência com base nestas diferentes necessidades. É preciso que, além do investimento em pesquisas com novos fármacos, exista um investimento em pesquisas qualitativas, que forneçam subsídios para um acompanhamento mais apropriado das pacientes.

Palavras-chave Adolescente, Violência sexual, Quimioprevenção, Adesão ao tratamento, Medicamentos, Representação social 


\section{Introdução}

A violência sofrida em idade precoce muitas vezes acomete a mulher que ainda não iniciou a vida sexual. Este fenômeno determina uma importante elevação no risco de contaminação pelo Vírus da Imunodeficiência Humana (HIV). Nos casos de violência sexual, especificamente, o risco de infecção pelo HIV é intensificado pela possibilidade de ocorrerem rupturas e dilacerações da pele da região genital ${ }^{1,2}$.

A taxa de infecções após violência sexual chega até $60 \%$ dos casos, com prevalência de 0,8 a $1,6 \%$ para a infecção pelo HIV, sendo esta a principal preocupação das suas vítimas ${ }^{1,2}$.

O risco de transmissão do HIV após a agressão sexual, embora pequeno, pode ser significativo em certas circunstâncias, sendo, portanto, razoável que a profilaxia pós-exposição seja oferecida, embora existam evidências de que a mesma tenha limitações ${ }^{3}$. Além disso, no caso de vítimas adolescentes as exigências de ordem psicológicas e jurídicas, além de médicas, são ainda mais preementes.

Segundo o Ministério da Saúde, a quimioprofilaxia do HIV deve ser considerada uma emergência e iniciada imediatamente após a violência, ainda nas primeiras 24 horas. $\mathrm{O}$ esquema deve ser mantido sem interrupção por quatro semanas consecutivas. A adesão à profilaxia antirretroviral é um dos fatores principais na redução do risco de transmissão da infecção pelo HIV. A falta de adesão ao esquema antirretroviral está diretamente relacionada ao risco de falha da profilaxia e de surgimento de cepas virais multirresistentes ${ }^{4}$.

Um número significativo de mulheres inicia a profilaxia para o HIV quando recebe o primeiro atendimento no serviço de referência. Isto se explica, em parte, pelo temor da vítima em adquirir HIV em função de uma violência sexual. Entretanto, verifica-se que menos da metade das mulheres completaram a profilaxia antirretroviral, evidenciando a grande necessidade de reformulação da assistência a esta população, em especial no que se refere ao seguimento ambulatorial dos casos ${ }^{5}$. Uma avaliação continuada do atendimento prestado deve ser efetivada para fins de identificação periódica dos casos de abandono do tratamento, na busca de alternativas viáveis para reduzir o risco de infecção pelo HIV².

Vários estudos têm mostrado que a falta de adesão à quimioprofilaxia do HIV é frequente em mulheres vítimas de violência sexual, podendo estar associada a diversos fatores como: trans- tornos psíquicos, efeitos colaterais dos medicamentos, aspectos socioeconômicos e qualidade do serviço de saúde di-3,-8. $^{1-5}$

Conhecer as dificuldades relacionadas ao uso de antirretrovirais permite a melhor compreensão da falta de adesão ao tratamento nos serviços brasileiros. Tal conhecimento pode contribuir para melhorar as políticas dirigidas a esse grupo e auxiliar os profissionais de saúde a lidar com essas dificuldades?.

Poucos estudos têm sido realizados especificamente sobre o uso da quimioprofilaxia antiHIV em adolescentes. É provável que adolescentes vítimas de violência sexual tenham particularidades relacionadas a esta fase do ciclo da vida, que interfiram na adesão a este tratamento. Assim, esta pesquisa objetivou conhecer, através de um estudo qualitativo, a representação social da violência sexual e sua relação com a adesão do protocolo da quimioprofilaxia do HIV em adolescentes e jovens, visando contribuir para o planejamento de ações direcionadas à diminuição dos riscos de transmissão da infecção pelo HIV nesta população.

Nessa perspectiva, o estudo das representações elaboradas pelas adolescentes vítimas de violência sexual aqui desenvolvido buscou entender os sentidos elaborados pelas pacientes acerca de sua condição, considerando tanto risco para a doença quanto a violência sofrida, assim como as informações médicas que recebem do impacto destes conteúdos na condução de seus tratamentos. Para que o profissional de saúde possa propor mudanças na sua decisão de adesão ao tratamento, é preciso entender o que influencia as ações dos adolescentes e as representações construídas por eles.

Consideramos, assim, que o estudo das representações sociais é fundamental para a compreensão da relação entre violência sexual e profilaxia, pois é a partir delas que o indivíduo se conduz no ambiente social, material e ideativo, e opta por continuar ou não um tratamento. Isso porque, no processo de elaboração da representação, há predominância do social sobre o individual, uma vez que o pensamento social é produzido coletivamente ${ }^{10}$. O que significa que preconceitos sociais podem influenciar um indivíduo a continuar ou não um tratamento.

A importância do estudo das representações sociais relativas a determinadas doenças e seus tratamentos está, assim, no fato de que elas orientam a conduta e a comunicação social e estabelecem uma realidade sociocultural comum. Isto ocorre porque a Representação Social (RS) pode 
também ser definida como uma forma de conhecimento do "senso comum". Ela está diretamente relacionada à maneira como as pessoas interpretam ou traduzem os conhecimentos veiculados socialmente. O processo de assimilação do conhecimento é sempre ativo, já que as pessoas entendem e assimilam as informações de acordo com os referenciais que possuem: os indivíduos vão reelaborar o saber científico segundo sua própria "conveniência", ou seja, de acordo com os meios e recursos que têm ${ }^{11}$.

As representações sociais são, nesse sentido, elementos simbólicos que os indivíduos expressam mediante o uso de palavras e de gestos. No caso do uso de palavras, utilizando-se da linguagem oral ou escrita, explicitam o que pensam, como percebem as situações e que opinião formulam acerca de determinado fato ou objeto. Essas mensagens, mediadas pela linguagem, são construídas socialmente e estão, necessariamente, ancoradas no âmbito da situação real e concreta dos indivíduos que as emitem ${ }^{12}$.

Quando falamos em representações sociais, acreditamos que elas são elaborações mentais construídas socialmente, a partir da dinâmica que se estabelece entre a atividade psíquica do sujeito e o objeto do conhecimento ${ }^{12}$. No caso aqui estudado, buscamos entender essas elaborações mentais construídas por adolescentes vítimas de violência sexual em torno dos significados tanto da possibilidade de contágio com o HIV, quanto dos tratamentos que deveriam seguir após a violência sofrida.

\section{Metodologia}

Realizou-se uma pesquisa de natureza descritiva, exploratória, com abordagem qualitativa, orientada pela teoria das representações sociais. A abordagem qualitativa apresenta-se como uma orientação cada vez mais difundida no âmbito da atividade cientifica na atualidade ${ }^{13}$. A singularidade da pesquisa qualitativa permite a possibilidade de descrever, decodificar, interpretar e compreender o sentido (ou sentidos) atribuído a fenômenos dentro do mundo social ${ }^{14}$.

O campo da pesquisa foi o Serviço de Apoio à Mulher Wilma Lessa (SAM-WL) no Hospital Agamenon Magalhães, situado em Recife (PE), que funciona como referência desde 2001, atendendo mulheres de qualquer idade, que tenham sofrido algum tipo de violência (doméstica, física, moral, sexual). $\mathrm{O}$ atendimento é realizado por uma equipe multiprofissional, formada por mé- dicos, assistentes sociais, psicólogos e enfermeiras, que garantem o sigilo da paciente.

Os sujeitos desta investigação foram mulheres jovens e adolescentes na faixa etária de 10-24 anos. Foi utilizado o critério de divisão de faixa etária estabelecido pela Organização Mundial da Saúde, que circunscreve a adolescência à segunda década da vida (de 10 a 19 anos de idade) e considera que a juventude se estende dos 15 aos 24 $\operatorname{anos}^{15}$.

Participaram do estudo as mulheres vítimas de violência sexual que procuraram o serviço dentro das primeiras 72 horas e receberam quimioprofilaxia antirretroviral para infecção pelo HIV (terapia antirretroviral tríplice, com utilização de Zidovudina, Indinavir e Lamivudina). Foram excluídas do estudo as pacientes com sorologia positiva para o HIV prévia à violência sexual.

A coleta de dados foi realizada no período de janeiro a setembro de 2012, obedecendo a seguinte sequência de trabalho: 1- Análise dos prontuários dos últimos seis meses de atendimento com o objetivo de listar as pacientes, como também para verificar as datas de agendamento do retorno ambulatorial o perfil sócio-econômico-demográfico das pesquisadas. 2- Aplicação do roteiro de entrevista semiestruturada, composta de cinco questões norteadoras.

Após aprovação pelo Comitê de Ética em Pesquisa em Seres Humanos do Hospital Agamenon Magalhães, as adolescentes foram convidadas a participar da pesquisa nos dias agendados para as consultas de retorno. Aquelas que não compareceram à consulta agendada foram convidadas a participar da pesquisa através de contato telefônico. Foi realizada a explicação dos objetivos da pesquisa e a assinatura do termo de consentimento livre e esclarecido pela participante e, quando esta era menor de 18 anos, a assinatura também pelo seu responsável ${ }^{16}$.

As entrevistas foram registradas com gravador de voz digital e transcritas na íntegra, de forma detalhada, em um período não superior às 24h, permitindo a análise segundo a técnica de análise de conteúdo ${ }^{17}$, à luz do referencial teórico das representações sociais.

As representações sociais fornecem ao pesquisador uma noção de existência de formas diversas de conhecimento entre pessoas leigas de grupos distintos, fornecendo também ideias sobre a quantidade de conhecimento produzido, transformado e transmitido ${ }^{18}$.

Assim, os resultados foram apresentados, destacando-se as informações obtidas conforme 
a relevância, cuja análise procedeu-se com base em referenciais teóricos de autores que realizaram estudos relacionados à temática. A amostragem foi definida mediante critério de saturação do conteúdo abordado.

Para garantir o anonimato das pesquisadas, nos fragmentos das entrevistas, foram utilizados os seguintes códigos: E (para entrevistado) e, após esse código, um número correspondente à sequência das entrevistas.

\section{Resultados}

A amostra desta pesquisa totalizou 13 mulheres, com idades entre 12 e 23 anos. Do total, apenas uma conhecia o agressor. Nove mulheres foram abordadas em via pública, duas na própria residência, uma no ambiente de trabalho e uma na residência do agressor. A maioria se autodeclarou da raça parda e com baixa escolaridade. Apenas duas tinham ensino médio completo e duas tinham ensino superior incompleto. Quanto ao estado civil, apenas uma era casada. A renda familiar mensal declarada foi em média de 1 a 2 salários mínimos. Quatro entrevistadas desistiram do tratamento profilático antes da sua conclusão. Nove participantes não concluíram o acompanhamento ambulatorial, realizando em média apenas dois retornos.

Verificou-se que o grupo estudado compartilhava uma representação da violência sexual percebendo-a acima de tudo como uma agressão sofrida sem justificativa e com uso de força, trazendo lembrança de sofrimento físico e emocional e os sentimentos de raiva e frustração pela incapacidade diante do agressor. Além disso, as representações que essas jovens e adolescentes fizeram da violência permitiu que as mesmas se percebessem como vítimas, como nos trechos abaixo citados:

Sei lá, vem uma tristeza vem... quando eu lembro pra mim eu acho que deveria ter feito alguma coisa teria corrido não sei [...] (E-04)

Eu não gosto nem de lembrar, eu evito, mudo logo, penso em outra coisa. Prefiro nem lembrar. (E-06)

As vezes penso em justiça, as vezes sinto muito medo [...] (E-07)

Durante a análise das transcrições, foi possível ainda observar a pouca familiaridade das entrevistadas, tanto com a condição de risco em contrair o HIV quanto com o tratamento profilático. Como pode ser verificado nas falas a seguir, fica claro que a lembrança da violência ain- da está muito presente e as jovens ainda não foram despertadas para as possíveis consequências. As lembranças da violência sofrida parecem atrapalhar o entendimento da importância da realização do tratamento, e isto se agrava pelo fato da própria complexidade do tratamento, considerando o número de comprimidos diários, a rigidez dos horários e os efeitos colaterais. O fato de tomar medicações na ausência de doença dificulta a aceitação ao tratamento. Os trechos a seguir ilustram esta situação:

Um pouco [...] porque eu não sou acostumada a tomar comprimido. Engolir os comprimidos [...] (risos). Só [...] Também porque assim eu fico me sentindo muito enjoada, muita dor de cabeça, é tão ruim. (E-01)

Por mim mesma, por atraso de horário tudinho... quando eu ia tomar já tava atrasado. Foi por causa disso mesmo eu não gosto de tomar remédio, muito comprimido, cada comprimido grandão, parecia um elefante. (E-02)

As representações sobre o tratamento profilático para o HIV expõem a ambiguidade de sentimentos envolvidos e indicam que as pesquisadas, ora se sentem seguras pelo tratamento recebido, sendo este aqui representado pelo estímulo para continuar através do apoio familiar recebido e as orientações fornecidas pelos profissionais de saúde durante o atendimento; ora experimentam a incerteza, representada pelas dificuldades encontradas. Estas incluem: dúvidas quanto à eficácia do protocolo profilático, efeitos indesejados dos fármacos utilizados como náusea e enjoos, a ideia de que algo ruim possa acontecer após o ato de violência, tristeza, e preocupações geradas aos familiares. Além disso, estas mulheres ainda têm que lidar com as representações sociais mais comuns acerca da violência em seu grupo social e experimentam, em sua maioria, a sensação de culpa e o medo de serem estigmatizados. Esta duplicidade de representação pode ser percebida, em alguns trechos.

As consequências depois, eu pensava logo em ter alguma coisa e, ainda penso né até hoje tenho medo. (E-10)

Porque o maior medo da minha vidaé de pegar uma doença ai eu disse nunca e, ainda mais por uma pessoa que eu não conheço tô nesse sofrimento todinho e eu pegar uma doença eu vou sofrer muito mais, Deus me livre eu jamais vou deixar de tomar esses remédios. (E-07)

Porém, apesar de todo o destaque dado para os benefícios do protocolo quimioprofilático pós-exposição à violência sexual, e estes serem reconhecidos pelas entrevistadas, as repercussões 
relacionadas às dificuldades com os efeitos colaterais parecem mesmo se tornar um obstáculo para a adesão aos antirretrovirais, como enfatizado pelos sujeitos do estudo. Os recortes das falas a seguir nos mostram que a presença de reações adversas aos medicamentos durante o tratamento pode atrapalhar a sua adesão, ou ainda, tornar-se um fator para a desistência. Os relatos apontaram as dificuldades enfrentadas, distribuindo-se em diferentes motivos. Dentre os mais citados estão os enjoos e náuseas, e os episódios de vômitos.

$E$ É...] são muitos enjoos, você fica até sem vontade de comer, você tá comendo dá aquele enjoo da vontade de você parar de comer naquela hora. (E06)

No começo é horrível porque a gente pensa mesmo é em 'desisti' que é todo dia ter que tomar aquilo dali, sempre que você toma 'senti' mal estar, sempre dá um enjoo, sempre dá alguma coisa, sai umas manchinhas na pele que é feio. Você não 'senti' o gosto da comida direito, tudo pra você fica ruim, sente dor porque a medicação é muito forte dá dor no estômago, ai tem que comer com leite, isso se torna chato na frequência diária que é horrível. (E-07)

Vale ressaltar que no presente estudo não foi constatada nenhuma rotina estabelecida para prevenir ou minimizar os efeitos colaterais do tratamento, apenas a equipe coloca-se a disposição para ajudar se "houver problemas". Sendo este um desafio para os profissionais, o controle dos efeitos indesejáveis, quando muitas vezes não há meios disponíveis no serviço e o paciente não dispõe de recurso para adquiri-los. Como podemos perceber no seguinte recorte:

Podia ter me dito que eu teria o enjoo, ter prescrito logo o remédio, se tivesse enjoo e se o remédio tivesse... Pro serviço pra poder dar essas orientações, porque é muito ruim você ficar tomando, você sabe que tem que tomar, você não sabe que fazer porque 'tá' enjoada você acha que o enjoo é normal, você tem como evitar o enjoo e não saber disso, você depois descobrir isso é horrível, você saber que poderia ter descoberto antes [...] (E-09)

Não há como negar que os fatores psicológicos são importantes obstáculos para a adesão ao tratamento. Algumas entrevistadas atribuem o desânimo, a falta de esperança, os sentimentos negativos e as lembranças da violência como dificuldades para continuar o tratamento, como ilustram os recortes a seguir.

Eu chorava, eu chorava lembrava de tudo pra mim aquilo poderia não ter acontecido. Se não tivesse acontecido aquilo comigo eu não 'taria' tomando tudo isso. (E-04)
Mais difícil foi ver minha mãe preocupada comigo, chorando, mais difícil foi ver minha mãe triste pelo que aconteceu... eu também fiquei triste ate hoje é uma coisa que a gente nunca esquece. $\mathrm{Na}$ hora de ver aquele remédio, ate o cheiro me deixava enjoada, quando colocava na boca sempre dava vontade de vomitar. (E-05)

É o pensamento da gente [...] o que dá raiva é que a gente 'tá' tomando aquilo ali porque uma pessoa nos fez um mal, acho que é a pior sensação que tem o pior momento de tomar os remédios, quando a gente bota o ele na boca, e tá pensando que tá passado por aquilo dali pelo uma pessoa que a gente nem conhece e fez aquilo com a gente. (E-07)

Tentando evitar situações geradoras de preconceitos e estigma, as pessoas que sofreram violência sexual muitas vezes preferem omitir o fato de que tomam os remédios, para evitar assim os questionamentos, selecionam cuidadosamente às pessoas que podem tomar conhecimento dessas circunstâncias e do tratamento oferecido após o ocorrido. O apoio da família aparece como um fator facilitador para a continuidade do tratamento, como demonstrado nos recortes:

Minha mãe 'tava' no meu pé porque eu dizia mãe eu não quero não esse remédio é muito ruim dá vontade de vomitar [...] ela dizia você tem que tomar você tem que tomar pro seu bem, ai tomei tudinho... Não desisti por causa dos conselhos que minha mãe me deu, sabendo que seria assim, esse remédio podia me salvar de alguns tipos de doença. (E-05)

De vez em quando o pessoal de casa lembrava dos horários, mas fora isso não. (E-08)

Porque minha tia 'tava' em cima, minha mãe e minha tia. (E-11)

[...] minha família toda, minha mãe, meus irmãos que moram perto [...] Está ali é... tentando the animar, tentando tirar isso da sua cabeça [...] porque não é fácil passar pelo que eu passei... então a pessoa chegava com um pensamento positivo [...] fazia uma oração, ficava olhando os horários, porque eu não 'tava' comendo, eu não 'tava' dormindo. $(\mathrm{E}-12)$

As informações obtidas pelas mulheres através dos profissionais de saúde durante os atendimentos também devem ser consideradas como estímulo para continuar o tratamento, esclarecendo os benefícios e os riscos para o momento que estas jovens e adolescentes vivenciam.

A doutora me explicou detalhadamente tudo 'né, o que eu ia passar com os comprimidos, o que eu ia passar em casa, as dificuldades. (E-01)

Me lembro não [...] pra tomar direito, não perder a hora. Eu acho que ele explicou, mas eu não lembro [...] só que eu não me lembro. (E-03) 
Disse que causa reações, enjoos, tonturas, mal estar, realmente aconteceu. (E-04)

Percebe-se também que o medo de adoecer por ter negligenciado o seu próprio tratamento, aparece como estímulo ao tratamento medicamentoso.

[...] depois veio a consciência pesada com medo que o safado tivesse Aids e eu [...] por conta 'deu' não ter tomado talvez eu ficar, por conta disso eu voltei a tomar. (E-04)

Foi pensar em não contrair nada, procurar sempre evitar [...] qualquer tipo de contágio que eu poderia ter se não tomasse a medicação e se principalmente pelo fato deu ter lido se eu interromper e tomasse de forma errada o medicamento eu poderia fortalecer ainda mais a Aids, não era uma coisa que realmente me agradaria. (E-08)

Continuar é bom pra não acontecer pior porque o que aconteceu comigo eu podia tá com alguma doença né, ai eu tomei o remédio todinho e 'tô' boa. (E-11)

\section{Discussão}

As representações sobre a violência sexual encontradas neste estudo estão em concordância com a revisão de literatura realizada por Almeida e Diniz ${ }^{19}$ para analisar a situação vivida pela mulher violentada. Esses autores apontam que na sociedade ocorrem relações desiguais entre homens e mulheres, nas quais as posições opostas de poder e subordinação, força e fraqueza, confrontam-se, e é neste cenário de poder que estão inseridas as relações violentas, as quais são aprendidas e reproduzidas. Salientam ainda que as vítimas de violência sexual sofrem com o preconceito, e ideias estereotipadas são concebidas e mitos são construídos a seu respeito. As situações críticas vivenciadas são verdadeiros empecilhos para o enfrentamento do problema e permeiam a realidade das mulheres em situação de violência.

As representações dos sujeitos por nós entrevistados acerca da violência e da profilaxia corroboram estas conclusões, enfatizando duas situações distintas encontradas pelas vítimas: dificuldades enfrentadas no tratamento e estímulos recebidos. Resultados semelhantes também foram encontrados por Silva et al. ${ }^{20}$ em estudo qualitativo, objetivando a compreensão a partir da perspectiva de portadores do HIV e familiares, dos aspectos que influenciaram na adesão à terapêutica antirretroviral. Esses autores também identificaram como aspectos que dificultam a adesão ao medicamento antirretroviral, a quan- tidade de medicamentos a ser ingerida, e a complexidade do tratamento, horários, efeitos colaterais. Além disso, também apontaram que o suporte oferecido por profissionais em relação ao tratamento, representado por apoio, informações adequadas sobre o tratamento e esclarecimentos sobre a gravidade dos efeitos colaterais, contribuiria para facilitar a adesão.

Como também foi verificado por Abrahams e Jewkes ${ }^{8}$, a incapacidade de lidar com os efeitos colaterais é um fator que contribui para a interrupção da medicação, sendo a adesão aos antirretrovirais, no período após o estupro, um processo desafiador. Neste estudo, aspectos como esquecimento, incompreensão dos benefícios do tratamento e regimes complicados, foram barreiras identificadas na adesão ao protocolo, assim como observado por Mills et al..$^{21}$. Estes autores salientaram ainda que sentimentos de autovalorização, percepção positiva com relação ao tratamento, aceitação do diagnóstico, uso de estratégias para lidar com o esquecimento e compreensão da necessidade de adesão, são considerados aspectos facilitadores.

De acordo com as diretrizes para o fortalecimento das ações de adesão ao tratamento para pessoas que vivem com HIV/Aids, a estratégia de acesso universal e gratuito do tratamento antirretroviral deve proporcionar uma maior adesão por parte das pacientes e que este tratamento tem sido priorizado nas políticas públicas de alguns países ${ }^{22}$. Além disso, diante da necessidade de manejar os efeitos indesejáveis causados pelo protocolo dos antirretrovirais, o Ministério da Saúde instituiu na norma técnica para prevenção e tratamento dos agravos resultantes da violência sexual contra mulheres e adolescentes, ser de fundamental importância que os profissionais de saúde prestem esclarecimentos sobre os possíveis efeitos adversos, bem como as medidas para minimizá-los, uma vez que a adesão ao tratamento diminui, quando interfere nas atividades cotidianas ou nos hábitos alimentares, ou quando acarreta muitos efeitos colaterais ${ }^{4}$.

Como observado nas falas deste estudo, essas estratégias ainda não são suficientes e são pouco utilizadas por parte dos profissionais de saúde. Mesmo quando a medicação é oferecida gratuitamente, diversos outros fatores influenciam a adesão ao tratamento, os quais vão desde o esquema terapêutico prescrito, incluindo o número de medicamentos, suas formas e horários, até a falta de preparo dos profissionais para um melhor acolhimento desta população.

Os esquemas terapêuticos normalmente são complicados e exigem um grande empenho por 
parte do paciente, que precisa adaptar sua alimentação, horários e ritmo diário para cumprir o tratamento. Somam-se a isso, os fatores emocionais envolvidos no contexto da violência sexual. Observou-se neste trabalho, que as vítimas encontram-se tão fragilizadas que percebem o tratamento como uma continuação do sofrimento causado pela violência, não dando o devido valor aos riscos decorrentes de sua interrupção, considerando que o mal maior já ocorreu.

Sabe-se que grandes esforços têm sido realizados na área de pesquisa para o desenvolvimento de novos fármacos, com melhores esquemas posológicos e efeitos colaterais reduzidos. Entretanto, devemos considerar que estes esforços poderão não ser suficientes para aumentar a adesão ao tratamento se não houver melhora no envolvimento e responsabilização dos profissionais que prestam atendimento a esta população, bem como no investimento no acolhimento social e psicológico das famílias envolvidas.

A aceitação e a adesão ao tratamento podem ser melhoradas com o suporte familiar. Nas representações construídas por essas jovens e adolescentes, a família está relacionada à ideia de suporte, apoio para enfrentar as dificuldades e vicissitudes da vida e talvez superar a falta de suporte social ${ }^{23}$. De acordo com o Fundo das Nações Unidas para a Infância ${ }^{24}$, os adolescentes apontam a família como instituição de referência como responsável pelo acesso aos seus direitos e garantia de bem estar. Nesse sentido, o apoio e o acolhimento das famílias podem contribuir para o enfrentamento das dificuldades por parte das vítimas de violência sexual.

Neste estudo, também foi percebido que os fatores emocionais e psicológicos como culpa, medo e ansiedade, podem influenciar no tratamento. Melhorar a assistência a esta população também é importante, quando se considera as consequências sobre a saúde mental resultantes da violência, e que estão relacionadas com as repercussões da violência em longo prazo na vida das vítimas, como a depressão, a ansiedade, os sentimentos de vergonha e culpa, as fobias e a síndrome de pânico, a inatividade física, a baixa autoestima e os distúrbios de estresse pós-traumático.

Deve-se considerar também a necessidade de trabalhar a diminuição da discriminação e do preconceito associados ao tratamento. Estes podem ter início, muitas vezes, no próprio núcleo familiar, havendo, desta forma, o isolamento social, correndo o risco de ser um fator a mais para dificultar a adesão medicamentosa. Segundo Kourrouski e Lima ${ }^{25}$, a partir do momento em que vivenciam situações de estigma e discriminação, as adolescentes passam a atribuir culpa ao tratamento por seus problemas, e o fato de a medicação trazer a lembrança desagradável é mais um motivo para a falta de adesão terapêutica.

Verificou-se que todas as dificuldades associadas ao tratamento quimioprofilático relatadas pelas pesquisadas poderiam ter sido trabalhadas pela equipe de saúde, que para Vonk et al. ${ }^{26}$, junto aos demais atores sociais, poderiam desempenhar um papel significativo, ampliando conhecimentos e fortalecendo as práticas de cuidados numa abordagem interdisciplinar, com assistência integral e humanizada.

Nos resultados deste estudo não foi encontrada nenhuma citação das participantes relacionadas às dificuldades econômicas para retornar ao serviço em busca do tratamento medicamentoso, apesar da baixa renda da maioria das entrevistadas. Esta condição pode ser explicada pelo fato de que todo o tratamento medicamentoso é dispensado na consulta inicial e as pacientes retornam ao serviço apenas para o acompanhamento ambulatorial. Assim, ao contrário do encontrado em outros estudos ${ }^{2,8}$, nesta pesquisa as dificuldades econômicas não foram entraves para a adesão ao tratamento.

\section{Conclusões}

Durante a realização desse estudo percebemos que o conjunto de representações sociais construídas nos grupos sociais de baixa renda da Região Metropolitana do Recife acerca da violência sexual, exerce considerável influência na adesão ou não das vítimas adolescentes aos tratamentos quimioprofiláticos. Os sujeitos pesquisados elaboraram imagens nas quais as preocupações geradas à família, os desconfortos causados pelos efeitos dos fármacos, a mudança de rotina, o medo de adoecer, de ser estigmatizada, a ansiedade, a raiva, aparecem como elementos constantes que acarretam o abandono do tratamento.

Consideramos, assim, que as reflexões sobre as experiências sociais ocorridas em decorrência da violência mostraram-se fundamentais para se compreender a situação dos entrevistados. E se tais representações podem influenciar no tratamento, cabe aos profissionais de saúde estar atentos a estas possibilidades, dispondo de recursos para planejar sua assistência com base nestas diferentes necessidades.

Entendemos que para ocorrer uma boa adesão, é preciso que vários fatores aconteçam em 
conjunto, que a paciente entenda e queira participar do tratamento, que exista confiança no profissional de saúde, recursos disponíveis para diminuir ou até sanar as dificuldades encontradas, suporte familiar, psicológico e social. E por tudo isso, também é preciso que, além do investimento em pesquisas com novos fármacos, exista um investimento em pesquisas qualitativas, que forneçam subsídios para um acompanhamento apropriado das vítimas/pacientes.

\section{Colaboradores}

EVP Procópio, CG Feliciano, CRT Katz e KVP Silva participaram igualmente de todas as etapas de elaboração do artigo.

\section{Referências}

1. Drezett J, Baldacini I, Nisida IVV, Nassif VC, Nápoli PC. Estudo da Adesão à quimioprofilaxia Antiretroviral para a Infecção por HIV em Mulheres Sexualmente Vitimadas. Rev Bras Ginecol Obstet 1999; 21(9):539-544.

2. Diniz NMF, Almeida LCG, Ribeiro BCS, Macêdo VG. Mulheres vítimas de violência sexual: adesão à quimioprofilaxia do HIV. Rev Latino-Am Enfermagem 2007; 15(1):7-12.

3. Steel-Duncan JC, Pierre R, Evans-Gilbert T, Rodriguez B, Christie CDC. HIV/AIDS following sexual assault in Jamaican children and adolescents: a case for HIV post-exposure prophylaxis. West Indian med J 2004; 53(5):352-355.

4. Brasil. Ministério da Saúde (MS). Prevenção e tratamento dos agravos resultantes da violência sexual contra mulheres e adolescentes: norma técnica. $3^{\mathrm{a}} \mathrm{ed}$. Brasília: MS; 2012.

5. Ramos CRA, Medici VPG. Puccia MIR. Mulheres vitimadas sexualmente perfil sociodemográfico e análise do atendimento em um centro de referência. Rev Inst Ciênc Saúde 2009; 27(1):22-27.

6. Schremmer RD, Swanson D, Kraly K. Human immunodeficiency virus postexposure prophylaxis in child and adolescent victims of sexual assault. Pediatr Emerg Care 2005; 21(8):502-506.

7. Olshen E, Hsu K, Woods ER, Harper M, Harnisch B, Samples CL. Use of Human Immunodeficiency Virus Postexposure Prophylaxis in Adolescent Sexual Assault Victims. Arch Pediatr Adolesc med 2006; 160(7):674-680.

8. Abrahams N, Jewkes R. Barriers to post exposure prophylaxis (PEP) completion after rape: a South African qualitative study. Culture Health \& Sexuality 2010; 2(5):471-484.

9. Melchior R, Nemes MIB, Alencar TMD, Buchalla CM. Desafios da adesão ao tratamento de pessoas vivendo com HIV/Aids no Brasil. Rev Saude Publica 2007; 41(2):87-93 
10. Minayo MCS, Souza ER. É possível prevenir a violência? Reflexões a partir do campo da saúde pública. Cien Saude Colet 1999; 4(1):7-32.

11. Moscovici S. Representações sociais: Investigações em psicologia social. $8^{\text {a }}$ ed. Petrópolis: Editora Vozes; 2011.

12. Franco MLPB. Representações sociais, ideologia e desenvolvimento da consciência. Cadernos de Pesquisa 2004; 34(121):169-186.

13. Bosi MLM. Pesquisa qualitativa em saúde coletiva: aportes aos sistemas de saúde. Cien Saude Colet 2012; 17(3):572-572.

14. Nunes ED. Ethical aspects considered by researchers who use qualitative approaches in health. Cien Saude Colet 2008; 13(2):351-360.

15. Brasil. Ministério da Saúde (MS). Secretaria de Atenção à Saúde. Área de Saúde do Adolescente e do Jovem. Marco legal: saúde, um direito de adolescentes. Brasília: MS; 2005.

16. Concone MHVB, Cerveny CMO. Research and the (free and) informed consent. Cien Saude Colet $2008 ; 13(2): 341-349$

17. Bardin L. Análise de conteúdo. Lisboa: Edições 70; 2011.

18. Flick U. Introdução à pesquisa qualitativa. $3^{\circ} \mathrm{ed}$. Porto alegre: Artmed; 2009.

19. Almeida LCG, Diniz NMF. Violência sexual: desvelando a realidade que acomete as mulheres. $R$ Enferm UERJ 2004; 12(1):88-94.

20. Silva ALCN, Waidman MAP, Marcon SS. Adesão e não-adesão à terapia anti-retroviral: as duas faces de uma mesma vivência. Rev Bras Enferm 2009; 62(2):213-220.

21. Mills EJ, Nachega JB, Bangsberg DR, Singh S, Rachlis B, Wu P, Wilson K, Buchan I, Gill CJ, Cooper C. Adherence to HAART: a systematic review of developed and developing nation patient-reported barriers and facilitators. PLoS Med 2006; 3(11):438.
22. Brasil. Ministério da Saúde (MS). Secretaria de Vigilância em Saúde. Programa Nacional de DST e aids. Diretrizes para o fortalecimento das ações de adesão ao tratamento para pessoas que vivem com HIV/aids. Brasília: MS; 2007.

23. Melo MCB, Barros EN, Almeida AMLG. A Representação da violência em adolescentes de escolas da rede pública de ensino do Município do Jaboatão dos Guararapes. Cien Saude Colet 2011; 16(10): 4211-4221.

24. Fundo das Nações Unidas para a Infância (UNICEF). A voz dos adolescentes [Relatório de Pesquisa]. UNICEF/Fator OM/2002. [acessado $2007 \mathrm{abr}$ 23]. Disponível em: http://www.unicef.org.br/

25. Kourrouski MFC, Lima RAG, Adesão ao tratamento: vivências de adolescentes com HIV/AIDS. Rev Latino-am Enfermagem 2009 nov-dez [acessado 2014 abr 23];17(6): [cerca de 8 p.]. Disponível em: http:/ / www.redalyc.org/articulo.oa?id=281421912004

26. Vonk ACRP, Bonan C, Silva KS. Sexualidade, reprodução e saúde: experiências de adolescentes que vivem em município do interior de pequeno porte. Cien Saude Colet 2013; 18(6):1795-1807.

Artigo apresentado em 03/06/2013 Aprovado em 25/10/2013

Versão final apresentada em 04/11/2013 